\title{
Determinants of oral self-care in the Brazilian adult population: a national cross-sectional study
}

\section{Danielle BORDIN(a) Cristina Berger FADEL(b) Celso Bilynkievycz dos SANTOS(c) Cléa Adas Saliba GARBIN(a) Suzely Adas Saliba MOIMAZ(a) Nemre Adas SALIBA(a)}

(a) Universidade Estadual Paulista "Júlio de Mesquita Filho" - Unesp, Araçatuba School of Dentistry, Department of Pediatric and Social Dentistry, Araçatuba, SP, Brazil.

(b) Universidade Estadual de Ponta Grossa - UEPG, Department of Dentistry, Ponta Grossa, PR, Brazil.

(c) Universidade Tecnoógica Federal do Paraná - UTFPR, Ponta Grossa, PR, Brazil.

Declaration of Interest: The authors certify that they have no commercial or associative interest that represents a conflict of interest in connection with the manuscript.

\section{Corresponding Author:}

Danielle Bordin

E-mail: daniellebordin@hotmail.com

hitps://doi.org/10.1590/1807-3107bor-2017.vol31.0115

Submitted: Apr 23, 2017

Accepted for publication: Oct 10, 2017

Last revision: Nov 23, 2017

\begin{abstract}
This study aims to investigate variables related to adherence to oral self-care in the Brazilian adult population. It is an exploratory study, using secondary data from a population-based survey on a representative sample of the adult population of the entire Brazilian territory $(\mathrm{n}=60202)$. The sample was selected using a multiple stage approach. The oral self-care indicator was defined by grouping the variables: periodicity of dentist appointments, use of dental floss, toothbrush and toothpaste, frequency of brushing and replacement of the toothbrush. The scores obtained from the indicator were categorized into adequate, partially adequate, and inadequate care. Statistical analysis consisted of dimensionality reduction, and oral self-care-related variables were submitted to logistic regression. The variables mostly related to inadequate or partially adequate oral self-care were: illiteracy ( $\mathrm{OR}=11.20, \mathrm{OR}=4.81)$, low educational level $(\mathrm{OR}=3.50, \mathrm{OR}=1.96)$, negative oral health self-concept $(\mathrm{OR}=3.73$, $\mathrm{OR}=1.74)$, absence of natural teeth $(\mathrm{OR}=4.98, \mathrm{OR}=2.60)$, edentulous lower arch ( $\mathrm{OR}=3.09$;______ $)$, number of missing upper teeth $(\mathrm{OR}=1.14$, $\mathrm{OR}=1.05)$, absence of health insurance $(\mathrm{OR}=2.23, \mathrm{OR}=2.07)$, sedentary lifestyle $(\mathrm{OR}=2.77, \mathrm{OR}=1.51)$, and smoking $(\mathrm{OR}=2.18$, $\mathrm{OR}=1.40)$. It was concluded that the individual's level of education is one of the main factors for adherence to adequate oral self-care, followed by level of oral health self-concept and tooth loss. Likewise, lifestyle also bears a significant influence.
\end{abstract}

Keywords: Self Care; Oral Health; Knowledge; Health Knowledge, Attitudes, Practice; Cross-Sectional Studies.

\section{Introduction}

The World Health Organization (WHO) defines self-care as the ability of individuals, families, and communities to promote quality of life, prevent disease and maintain health, and cope with disease and disability with or without the support of a healthcare practitioner. ${ }^{1,2}$ Generally speaking, self-care can be defined simply as the practice of voluntary and intentional activities that individuals perform for their own benefit and for the purpose of preserving life, health, and wellbeing. ${ }^{3}$

Authors advocate that self-care should assume a central role in the field of social and preventive healthcare, since the current objective of 
health interventions is more related to the response given to life processes than to the disease itself. ${ }^{4,5}$

Self-care may be affected by basal factors such as age, sex, education, income, health condition and support network, ${ }^{6}$ and by distal factors such as sociocultural orientation, family issues and environment, lifestyle, and adequacy and availability of public resources ${ }^{6}$. In the field of oral health, the recognition and analysis of the process of acquiring individual autonomy is under construction, and studies predominantly show an association between oral self-care and isolated factors. ${ }^{7,8,9,10,11}$

The literature points out that appropriate oral health depends on maintaining certain practices, including periodic dental visits, ${ }^{12,13,14,15}$ tooth brushing frequency, ${ }^{7,10,12,16,17}$ toothbrush replacement frequency, ${ }^{17,18}$ dental flossing, and use of auxiliary techniques, ${ }^{7,12,17,19}$ and that all these factors together represent oral selfcare. However, the studies usually evaluate oral selfcare in a segmented manner, relating it specifically to dental flossing, toothbrushing or regular visits to the dentist. $78,10,16,17$ Therefore, the factors that actually infer oral self-care cannot be predicted accurately.

The objective of this study was to investigate multiple variables related to adherence to oral self-care in the Brazilian adult population, using an indicator that encompasses several factors representing oral healthcare. Knowing these variables makes it possible to identify health standards and behaviors, which can influence the development of oral healthcare policies focusing on self-care determinants, and the introduction of supported strategies to strengthen oral self-care.

\section{Methods}

This was a cross-sectional, quantitative study carried out with data from the last National Health Survey (PNS), developed in 2013, and financed by the Brazilian Ministry of Health ${ }^{20}$, with the approval of the National Human Research Ethics Committee, Resolution \# 328.159/2013.

The National Health Survey was conducted by the Brazilian Institute of Geography and Statistics (IBGE), which is the main provider of data and information in the country, and which carefully followed all the statistical and methodological steps recommended for this type of research, in order to obtain concise and representative data on the entire Brazilian territory. ${ }^{20}$

The PNS was developed in households covering the entire Brazilian territory, ${ }^{20}$ using a cluster sampling ${ }^{20}$ to obtain estimated data of the proportion of people in the different categories of the indicators of interest. The data were collected from 64,348 homes, and interviews with 60,202 adults. Details on the sampling and deliberation process are available in the PNS report. ${ }^{20}$

Calibrated researchers performed the data collection, and the interviews were recorded on handheld computers. After explaining the objectives, procedures, and importance of participating in the research to the interviewees, the accepting participants were identified, that is, the individuals who answered the questionnaire and all the residents of the home, as well as the adults who were selected by drawing, and who answered the individual questionnaire, and also continued on to the other stages of the research. ${ }^{20}$

The survey was composed of three forms: the home form, referring to the characteristics of the home; the home resident form; and the individual form, answered by the residents who were selected by the drawing, and who were aged 18 years or older. ${ }^{20}$ In this study, the individual and the home resident forms were used; however, only the answers provided by the interviewed participants were entered in the home resident form.

The forms were presented in thematic modules. Each module composed a set of variables that made it possible to characterize several topics of interest in greater detail. ${ }^{21}$

\section{Processing of data}

\section{Variable outcome}

The broad oral self-care indicator was considered a variable outcome, and was created by grouping together preexisting variables in the form. ${ }^{21}$ The variables were selected to represent the oral selfcare indicator as closely as possible, and comprised: the time since the last dental appointment (response pattern: in the last 12 months, over 1 and under 2 years, over 2 years, and never went to the dentist); brushing frequency (response pattern: twice a day or more, once a day, does not brush every day, never brushed); materials used for oral-health (toothbrush, 
toothpaste and dental floss - yes and no for the response pattern), and toothbrush replacement frequency (response pattern: less than 3 months, between 3 and 6 months, between 6 months and 1 year, more than once a year, and never replaced).

In this stage in which the variable was created, each variable was dichotomized and evaluated as appropriate oral self-care (score 1), according to the conditions considered acceptable by the literature, namely: dental appointment made at least once a year, ${ }^{12,16}$ tooth brushing twice a day or more, ${ }^{18}$ use of toothbrush, toothpaste and floss, and replacement of toothbrush within less than 6 months; ${ }^{22}$ or inadequate self-care (score 0 ), considered as consisting of the worst conditions.

In creating the oral self-care indicator, the variables were grouped together according to the sum of the scores obtained. When the sum was equal to 0 or 1 , the oral self-care was considered entirely inadequate, 2 to 5 meant partially adequate, and equal to 6 meant entirely adequate (Figure 1).

The accuracy of the indicator was verified by applying a decision tree test, where the indicator was considered a variable outcome, and the training variables as explanatory variables. In so doing, we achieved an explanatory capacity (99.99\%) of the variables under the broad indicator of oral self-care, with an error estimate of $0.0087 \%$. In the model created, the variable with the greatest explanatory capacity was use of dental paste, followed by use of dental floss and toothbrush replacement frequency.

\section{Independent variables}

The following variables related to the thematic modules were selected: general characteristics of the residents, education, work, health insurance coverage, health services used, lifestyle, health perceptions, chronic diseases, and oral health, ${ }^{21}$ totaling 66 variables of interest. After exploring these data, 40 variables were included in the study, all of which were treated according to the pertinent literature. The numerical variables were categorized, and some categorical variables were dichotomized or re-categorized. In the next step, the variables underwent descriptive analysis, as presented in the results section (Tables 1, 2, 3).

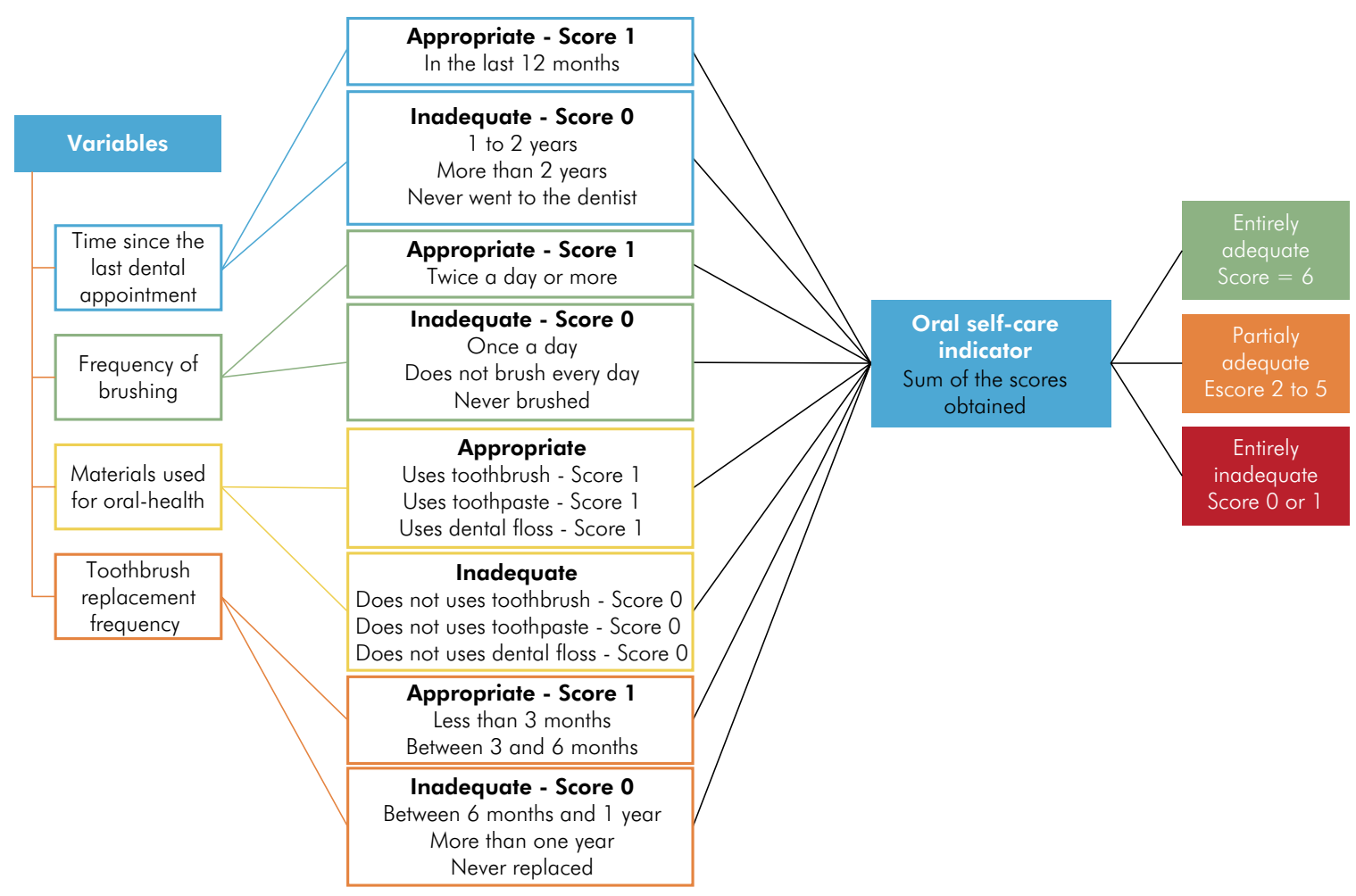

Figure 1. Process of forming the dependent variable of 'oral self-care'. 
Table 1. Description of the sample, according to sociodemographic and work characteristics. Brazil. 2013. ( $\mathrm{n}=60202)$.

\begin{tabular}{|c|c|c|c|c|c|c|c|c|c|}
\hline \multirow{3}{*}{$\begin{array}{l}\text { Variables } \\
\text { Dependent variable } \\
\text { Oral self-care }\end{array}$} & \multirow{3}{*}{ Class } & \multicolumn{2}{|c|}{ Total } & \multicolumn{2}{|c|}{ Entirely inadequate } & \multicolumn{2}{|c|}{ Partially adequate } & \multicolumn{2}{|c|}{ Entirely adequate } \\
\hline & & $\mathrm{n}$ & $\%$ & $n$ & $\%$ & $\mathrm{n}$ & $\%$ & $\mathrm{n}$ & $\%$ \\
\hline & & 60202 & 100 & 1392 & 2 & 36696 & 61 & 22114 & 37 \\
\hline \multicolumn{10}{|l|}{ Independent variables } \\
\hline \multicolumn{10}{|l|}{ Sociodemographic characteristics } \\
\hline \multirow{2}{*}{ Gender } & Male & 25920 & 43 & 667 & 48 & 17232 & 47 & 8021 & 36 \\
\hline & Female & 34282 & 57 & 725 & 52 & 19464 & 53 & 14093 & 64 \\
\hline \multirow{5}{*}{ Age } & $18 \leq 30$ & 15750 & 26 & 16 & 1 & 8654 & 24 & 7080 & 32 \\
\hline & $31 \leq 40$ & 14139 & 23 & 35 & 3 & 7666 & 21 & 6438 & 29 \\
\hline & $41 \leq 50$ & 11160 & 19 & 73 & 5 & 6724 & 18 & 4363 & 20 \\
\hline & $51 \leq 60$ & 10426 & 17 & 244 & 18 & 5945 & 16 & 4237 & 19 \\
\hline & $>60$ & 8727 & 14 & 1024 & 74 & 7707 & 21 & 0 & 0 \\
\hline \multirow{6}{*}{ Ethnicity } & White & 24106 & 40 & 481 & 35 & 12913 & 35 & 10712 & 48 \\
\hline & Black & 5631 & 9 & 159 & 11 & 3831 & 10 & 1641 & 7 \\
\hline & Asian & 533 & 1 & 11 & 1 & 287 & 1 & 235 & 1 \\
\hline & Mixed-race & 29512 & 49 & 735 & 53 & 19371 & 53 & 9406 & 43 \\
\hline & Indian & 417 & 1 & 6 & 0 & 292 & 1 & 119 & 1 \\
\hline & Ignored & 3 & 0 & 0 & 0 & 2 & 0 & 1 & 0 \\
\hline \multirow{2}{*}{ Living with spouse or partner } & Yes & 34522 & 57 & 556 & 40 & 20992 & 57 & 12974 & 59 \\
\hline & No & 25680 & 43 & 836 & 60 & 15704 & 43 & 9140 & 41 \\
\hline \multirow{4}{*}{ Marital status } & Married & 23741 & 39 & 485 & 35 & 13882 & 38 & 9374 & 42 \\
\hline & Separated or Divorced & 4727 & 8 & 106 & 8 & 2759 & 8 & 1862 & 8 \\
\hline & Widow (er) & 4708 & 8 & 440 & 32 & 3413 & 9 & 855 & 4 \\
\hline & Single & 27026 & 45 & 361 & 26 & 16642 & 45 & 10023 & 45 \\
\hline & Yes & 54335 & 90 & 710 & 51 & 31795 & 87 & 21830 & 99 \\
\hline Literacy & No & 5867 & 10 & 682 & 49 & 4901 & 13 & 284 & 1 \\
\hline & Literacy & 7630 & 13 & 532 & 38 & 6259 & 17 & 839 & 4 \\
\hline & Primary School & 15288 & 25 & 190 & 14 & 11382 & 31 & 3716 & 17 \\
\hline & Secondary School & 18589 & 31 & 91 & 7 & 9927 & 27 & 8571 & 39 \\
\hline Level of education & Undergraduate & 8109 & 13 & 13 & 1 & 2805 & 8 & 5291 & 24 \\
\hline & Graduate & 487 & 1 & 0 & 0 & 117 & 0 & 370 & 2 \\
\hline & Not applicable & 10099 & 17 & 566 & 41 & 6206 & 17 & 3327 & 15 \\
\hline & North & 12536 & 21 & 205 & 15 & 8266 & 23 & 4065 & 18 \\
\hline & Northeast & 18305 & 30 & 614 & 44 & 12482 & 34 & 5209 & 24 \\
\hline Region of residence & Southeast & 14294 & 24 & 352 & 25 & 7741 & 21 & 6201 & 28 \\
\hline & South & 7548 & 13 & 107 & 8 & 3973 & 11 & 3468 & 16 \\
\hline & Midwest & 7519 & 12 & 114 & 8 & 4234 & 12 & 3171 & 14 \\
\hline Work characteristics & & & & & & & & & \\
\hline & Yes & 33990 & 56 & 241 & 17 & 19043 & 52 & 14706 & 67 \\
\hline Has a paid job & No & 26212 & 44 & 1151 & 83 & 17653 & 48 & 7408 & 33 \\
\hline & Domestic Work & 2784 & 5 & 30 & 2 & 1885 & 5 & 869 & 4 \\
\hline & Private sector employee & 16267 & 27 & 67 & 5 & 8692 & 24 & 7508 & 34 \\
\hline & Public sector employee & 5841 & 10 & 13 & 1 & 2364 & 6 & 3464 & 16 \\
\hline Occupation & Employer & 1023 & 2 & 1 & 0 & 459 & 1 & 563 & 3 \\
\hline & Free-lancer & 10092 & 17 & 155 & 11 & 6878 & 19 & 3059 & 14 \\
\hline & Unpaid worker & 435 & 1 & 10 & 1 & 305 & 1 & 120 & 1 \\
\hline & Not answered & 23760 & 39 & 1116 & 80 & 16113 & 44 & 6531 & 30 \\
\hline & One & 34776 & 58 & 270 & 19 & 19843 & 54 & 14663 & 66 \\
\hline Number of jobs & Two or more & 1666 & 3 & 6 & 0 & 740 & 2 & 920 & 4 \\
\hline & Not applicable & 23760 & 39 & 1116 & 80 & 16113 & 44 & 6531 & 30 \\
\hline & $\leq 216$ dollars & 11661 & 19 & 166 & 12 & 8276 & 23 & 3219 & 15 \\
\hline & $216>421$ dollars & 12319 & 20 & 62 & 4 & 7096 & 19 & 5161 & 23 \\
\hline Income & $420>841$ dollars & 6988 & 12 & 30 & 2 & 3330 & 9 & 3628 & 16 \\
\hline & $>840$ dollars & 5027 & 8 & 8 & 1 & 1566 & 4 & 3453 & 16 \\
\hline & Not applicable & 24207 & 40 & 1126 & 81 & 16428 & 45 & 6653 & 30 \\
\hline & $\leq 20$ hours & 4264 & 7 & 63 & 5 & 2282 & 6 & 1919 & 9 \\
\hline & $20>41$ hours & 16576 & 28 & 120 & 9 & 8323 & 23 & 8133 & 37 \\
\hline Number of hours worked per week & $>40$ hours & 15602 & 26 & 93 & 7 & 8702 & 24 & 6807 & 31 \\
\hline & Not applicable & 23760 & 39 & 1116 & 80 & 17389 & 47 & 5255 & 24 \\
\hline & Yes & 5419 & 9 & 22 & 2 & 2834 & 8 & 2563 & 12 \\
\hline Works at night & No & 31023 & 52 & 254 & 18 & 17749 & 48 & 13020 & 59 \\
\hline & Not applicable & 23760 & 39 & 1116 & 80 & 16113 & 44 & 6531 & 30 \\
\hline
\end{tabular}


Table 2. Description of the sample, according to overall health conditions. Brazil. 2013. ( $n=60202)$.

\begin{tabular}{|c|c|c|c|c|c|c|c|c|c|}
\hline \multirow{2}{*}{ Independent variable } & \multirow{2}{*}{ Class } & \multicolumn{2}{|c|}{ Total } & \multicolumn{2}{|c|}{ Entirely inadequate } & \multicolumn{2}{|c|}{ Partially adequate } & \multicolumn{2}{|c|}{ Entirely adequate } \\
\hline & & $n$ & $\%$ & $\mathrm{n}$ & $\%$ & $\mathrm{n}$ & $\%$ & $\mathrm{n}$ & $\%$ \\
\hline \multicolumn{10}{|l|}{ Oral health condition } \\
\hline \multirow{2}{*}{$\begin{array}{l}\text { Self-concept of oral health } \\
\text { condition }\end{array}$} & Positive & 39572 & 66 & 613 & 44 & 21712 & 59 & 17247 & 78 \\
\hline & Negative & 20630 & 34 & 779 & 56 & 14984 & 41 & 4867 & 22 \\
\hline \multirow{2}{*}{ Difficulty eating } & None & 53336 & 89 & 984 & 71 & 34282 & 93 & 18070 & 82 \\
\hline & Some & 6866 & 11 & 408 & 29 & 2414 & 7 & 4044 & 18 \\
\hline \multirow{3}{*}{ Upper arch dental loss } & None & 22387 & 37 & 30 & 2 & 11359 & 31 & 10998 & 50 \\
\hline & Some & 26806 & 45 & 157 & 11 & 16528 & 45 & 10121 & 46 \\
\hline & All teeth missing & 11009 & 18 & 1205 & 87 & 8809 & 24 & 995 & 4 \\
\hline \multirow{3}{*}{ Lower arch dental loss } & None & 21133 & 35 & 42 & 3 & 10944 & 30 & 10147 & 46 \\
\hline & Some & 32121 & 53 & 186 & 13 & 20271 & 55 & 11664 & 53 \\
\hline & All teeth missing & 6948 & 12 & 1164 & 84 & 5481 & 15 & 303 & 1 \\
\hline \multirow{3}{*}{$\begin{array}{l}\text { Number of natural teeth } \\
\text { present }\end{array}$} & None & 6606 & 11 & 1144 & 82 & 5226 & 14 & 236 & 1 \\
\hline & $>10$ & 3413 & 6 & 100 & 7 & 2895 & 8 & 418 & 2 \\
\hline & $\leq 10$ & 50183 & 83 & 148 & 11 & 28575 & 78 & 21460 & 97 \\
\hline \multirow{5}{*}{ Use of dental prosthesis } & No & 24431 & 41 & 769 & 55 & 14731 & 40 & 8931 & 40 \\
\hline & $\begin{array}{l}\text { Yes, but needs to } \\
\text { replace some teeth }\end{array}$ & 14932 & 25 & 129 & 9 & 9619 & 26 & 5184 & 23 \\
\hline & & & & & & & & & \\
\hline & $\begin{array}{l}\text { Yes, but needs to } \\
\text { replace all teeth }\end{array}$ & 5558 & 9 & 470 & 34 & 4733 & 13 & 355 & 2 \\
\hline & Not answered & 15281 & 25 & 24 & 2 & 7613 & 21 & 7644 & 35 \\
\hline \multicolumn{10}{|l|}{ General health condition } \\
\hline \multirow{2}{*}{$\begin{array}{l}\text { Self-concept of general } \\
\text { health condition }\end{array}$} & Positive & 39141 & 65 & 492 & 35 & 21541 & 59 & 17108 & 77 \\
\hline & Negative & 21061 & 35 & 900 & 65 & 15155 & 41 & 5006 & 23 \\
\hline \multirow{2}{*}{ Limited mobility } & Yes & 1567 & 3 & 222 & 16 & 1101 & 3 & 244 & 1 \\
\hline & No & 58635 & 97 & 1170 & 84 & 35595 & 97 & 21870 & 99 \\
\hline \multirow{2}{*}{ Difficulty seeing } & Yes & 23859 & 40 & 557 & 40 & 13961 & 38 & 9341 & 42 \\
\hline & No & 36343 & 60 & 835 & 60 & 22735 & 62 & 12773 & 58 \\
\hline \multirow{2}{*}{ Alcohol consumption } & Yes & 23002 & 38 & 1146 & 82 & 23410 & 64 & 12644 & 57 \\
\hline & No & 37200 & 62 & 246 & 18 & 13286 & 36 & 9470 & 43 \\
\hline \multirow{2}{*}{ Practice of physical activity } & Yes & 17896 & 30 & 101 & 7 & 8432 & 23 & 9363 & 42 \\
\hline & No & 42306 & 70 & 1291 & 93 & 28264 & 77 & 12751 & 58 \\
\hline \multirow{2}{*}{ Tobacco use } & Yes & 8729 & 14 & 344 & 25 & 6340 & 17 & 2045 & 9 \\
\hline & No & 51473 & 86 & 1048 & 75 & 30356 & 83 & 20069 & 91 \\
\hline \multirow{2}{*}{$\begin{array}{l}\text { Presence of chronic } \\
\text { diseases }\end{array}$} & Yes & 27250 & 45 & 470 & 34 & 19377 & 53 & 7403 & 33 \\
\hline & No & 32952 & 55 & 922 & 66 & 17319 & 47 & 14711 & 67 \\
\hline
\end{tabular}


Table 3. Description of the sample, according to use of oral health services. Brazil. 2013. ( $\mathrm{n}=60202)$.

\begin{tabular}{|c|c|c|c|c|c|c|c|c|c|}
\hline \multirow[t]{2}{*}{ Independent variable } & \multirow[t]{2}{*}{ Class } & \multicolumn{2}{|c|}{ Total } & \multicolumn{2}{|c|}{$\begin{array}{c}\text { Entirely } \\
\text { inadequate }\end{array}$} & \multicolumn{2}{|c|}{$\begin{array}{l}\text { Partially } \\
\text { adequate }\end{array}$} & \multicolumn{2}{|c|}{$\begin{array}{l}\text { Entirely } \\
\text { adequate }\end{array}$} \\
\hline & & $\mathrm{n}$ & $\%$ & $n$ & $\%$ & $n$ & $\%$ & $n$ & $\%$ \\
\hline \multicolumn{10}{|l|}{ Use of oral health services } \\
\hline \multirow{4}{*}{ Reason for last dental appointment } & Prevention or checkup & 14048 & 23 & 21 & 2 & 4078 & 11 & 9949 & 45 \\
\hline & Treatment & 11144 & 19 & 83 & 6 & 5018 & 14 & 6043 & 27 \\
\hline & Other reasons & 464 & 1 & 1 & 0 & 188 & 1 & 275 & 1 \\
\hline & Not answered & 34546 & 57 & 1287 & 92 & 27412 & 75 & 5847 & 26 \\
\hline \multirow{4}{*}{ Duration of dental appointment } & $\leq 30$ minutes & 17088 & 28 & 81 & 6 & 6690 & 18 & 10317 & 47 \\
\hline & $30<61$ minutes & 7439 & 12 & 22 & 2 & 2220 & 6 & 5197 & 24 \\
\hline & $>60$ minutes & 1129 & 2 & 2 & 0 & 374 & 1 & 753 & 3 \\
\hline & Not applicable & 34546 & 57 & 1287 & 92 & 27412 & 75 & 5847 & 26 \\
\hline \multirow{4}{*}{ Dental appointment by } & Health insurance & 4744 & 8 & 9 & 1 & 1149 & 3 & 3586 & 16 \\
\hline & Private & 14042 & 23 & 43 & 3 & 4444 & 12 & 9555 & 43 \\
\hline & SUS & 6451 & 11 & 53 & 4 & 3405 & 9 & 2993 & 14 \\
\hline & Didn't know/ not answered & 34965 & 58 & 1287 & 92 & 27412 & 75 & 6266 & 28 \\
\hline \multirow{3}{*}{ Evaluation of the service received } & Positive & 23248 & 39 & 91 & 7 & 8116 & 22 & 15041 & 68 \\
\hline & Negative & 2408 & 4 & 14 & 1 & 1168 & 3 & 1226 & 6 \\
\hline & Not answered & 34546 & 57 & 1287 & 92 & 27412 & 75 & 5847 & 26 \\
\hline \multirow{3}{*}{ Individual health insurance } & Yes & 4744 & 8 & 5 & 1 & 1149 & 3 & 3590 & 16 \\
\hline & No & 20912 & 35 & 100 & 7 & 8135 & 22 & 12677 & 57 \\
\hline & Not answered & 34546 & 57 & 1287 & 92 & 27412 & 75 & 5847 & 26 \\
\hline
\end{tabular}

The variables related to chronic diseases, such as diabetes, hypertension, high cholesterol, stroke, chronic spinal problems, arthritis, work-related osteomuscular disturbances, depression, chronic obstructive pulmonary disease, cancer and chronic renal failure were analyzed with the variable outcome, but presented no associations. Hence, a new variable was created, called the presence of chronic disease (s), which groups all diseases aiming at increasing the representativeness of the presence or absence of some chronic diseases. In the results section, only the variable presence of chronic disease (s) was addressed.

The variable of number of natural teeth in the mouth was also created. In constructing this variable, we considered the totality of natural teeth present in the individual's whole mouth (32), subtracted from the sum of upper and lower missing teeth. Then, the variable was dichotomized according to the parameters of a previous study ${ }^{23}$, into more than 10 natural teeth and 10 or fewer natural teeth in the mouth.

After categorizing the results, an unbalance was observed in the classes of the outcome variable. To avoid bias of the results, the classes from the outcome variable were balanced for each independent variable, applying the Resample Weka Filter, using the supervised method. ${ }^{24}$

\section{Data analysis}

Once the database was delimited, the first statistical analysis was made, consisting of the dimensionality reduction test, performed using the Correlation-based Feature Selection (CFS) algorithm, according to the cross-validation method of 10-fold in the WEKA environment. ${ }^{24}$ This algorithm prioritizes different sets of attributes (independent variables) that are closely related to the outcome variable and little related to each other. Thus, the close relationship of the dependent variables with the independent variables can be verified with much greater precision than with other tests commonly used in the literature, since the researcher wields no influence during the analysis.

Next, the variables related to 'oral self-care' were evaluated by logistic regression, so that the magnitudes of the associations from the odds ratios could be verified, also performed in the WEKA environment. ${ }^{24}$ The confidence interval was set at $95 \%$, and statistical significance, at $p>0.05$. The model had an explanatory capacity of $70.4 \%$. 


\section{Results}

Tables 1, 2 and 3 describe the sample, according to 'oral self-care' and sociodemographic and work characteristics, overall health conditions and use of dental services, respectively.

The majority of the Brazilian population have partially adequate oral self-care (61\%), followed by totally adequate $(37 \%)$. The descriptive data show that the majority of individuals who presented entirely adequate oral self-care are young, white and mixed-race adults, married and single, with good schooling and good work conditions (Table 01). However, they are individuals who have positive conditions and self-perceptions of oral and general health, without experiencing pain and tooth loss, and without diseases and limitations, who practice regular physical activity and do not smoke (Table 02). In addition, individuals with fully satisfactory self-care usually seek more oral health services for prevention or checkup, with quick consultations, have an individual health insurance plan, and evaluate the service received positively (Table 3 ).

In the results of the attribute selection analysis, the variables most strongly related to oral self-care were literacy, level of education, self-concept of oral health, number of natural teeth, lower arch dental loss, number of missing upper teeth, use of health insurance, physical activity and smoking status. The reasons for the individual presenting inadequate or partially adequate oral self-care, according to the variables listed above, can be observed in Table 4.

\section{Discussion}

The present study is the first to address the oral self-care of the Brazilian adult population using a broad approach and data from a national survey, with a representative sample of the entire Brazilian territory. Survey results showed that there is a strong relationship between oral self-care and educational attainment, self-perception of oral health, number of natural teeth, lower arch dental loss, number of missing upper teeth, health insurance coverage, habit of practicing physical activity and tobacco use.
Table 4. Reasons for entirely inadequate and partially adequate oral self-care according to independent variables.

\begin{tabular}{|c|c|c|}
\hline Variable & $\begin{array}{c}\text { Entirely } \\
\text { Inadequate } \\
\text { (OR) }\end{array}$ & $\begin{array}{c}\text { Partially } \\
\text { Adequate } \\
\text { (OR) }\end{array}$ \\
\hline \multicolumn{3}{|l|}{ Literacy } \\
\hline Yes & 1.00 & 1.00 \\
\hline No & 11.20 & 4.81 \\
\hline \multicolumn{3}{|l|}{ Level of Education } \\
\hline Literacy & 3.50 & 1.96 \\
\hline Primary School & 1.68 & 1.42 \\
\hline Secondary School & 1.36 & ---- \\
\hline Graduate School & 1.00 & 1.00 \\
\hline \multicolumn{3}{|l|}{ Self-concept of oral health condition } \\
\hline Positive & 1.00 & 1.00 \\
\hline Negative & 3.73 & 1.74 \\
\hline \multicolumn{3}{|l|}{ Number of Natural Teeth } \\
\hline All natural teeth & 1.00 & 1.00 \\
\hline No natural teeth & 4.98 & 2.60 \\
\hline \multicolumn{3}{|l|}{ Lower Arch Dental Loss } \\
\hline No missing teeth & 1.00 & 1.00 \\
\hline All missing teeth & 3.09 & ---- \\
\hline Number of missing upper teeth & $1.14^{*}$ & $1.05^{*}$ \\
\hline \multicolumn{3}{|l|}{ Use of health insurance } \\
\hline Yes & 1.00 & 1.00 \\
\hline No & 2.23 & 2.07 \\
\hline \multicolumn{3}{|l|}{ Practice of Physical Activity } \\
\hline Yes & 1.00 & 1.00 \\
\hline No & 2.77 & 1.51 \\
\hline \multicolumn{3}{|l|}{ Tobacco use } \\
\hline Yes & 1.00 & 1.00 \\
\hline No & 2.18 & 1.40 \\
\hline
\end{tabular}

*Refers to each missing tooth

Some of the relevant aspects of this approach are the sample size, the instrument quality, and the information variability, represented by a significant number of validated questions about individual, sociodemographic, behavioral and lifestyle factors, as well objective and subjective factors related to oral health.

In addition, the creation of a variable that represents all the elements considered as characterizing oral selfcare by the literature ${ }^{7,8,10,12,17}$ is what makes this study so very distinct. As observed in the methodological 
description, the grouping of factors shows a high explanatory capacity, and the variable created can be used in other studies and in health planning involving more concrete strategies for self-care.

In contrast to this unprecedented broad indicator, oral self-care was found in the literature only in a segmented manner. Studies have shown that the higher frequency of tooth brushing was more commonly related to the female sex, $7,12,19,16$ better economic conditions, ${ }^{10,19}$ better educational level, ${ }^{16}$ absence of drinking alcohol ${ }^{10,16}$ and smoking, ${ }^{10,16}$ practicing physical activities regularly, ${ }^{8,10}$ and the type of health service used, whether public or private. ${ }^{7}$

One of the variables with greater explanatory capacity of oral self-care characterization was the use of dental floss. In this regard, people of high socioeconomic status reported using dental floss more than people of lower socioeconomic status. ${ }^{12,19}$ This finding may be related to the high cost of the product in Brazilian stores, and to the more limited knowledge about flossing among the lower classes ${ }^{12,19}$. Individuals who attend private dental offices also tend to use dental floss more often than those who do not use this type of service, ${ }^{7}$ a finding whose explanation lies in the greater probability that an individual receives oral hygiene instructions in the dental office. In addition, an individual with the purchasing power to go to a private dentist can also afford to buy dental floss and use it regularly. ${ }^{7}$ Notably, women tend to floss more than men. ${ }^{11,25}$

The type of health service used is considered an important element in the study of health habits, since it is related to treatment and self-care. ${ }^{7}$ Regarding the periodicity of visits to the dentist, low socioeconomic status, ${ }^{7,10,12}$ low level of education, ${ }^{13}$ men, ${ }^{13}$ self-perception of oral health, ${ }^{7,13}$ bad oral health condition, ${ }^{13,15}$ risky behavior, ${ }^{10}$ reduced physical activity ${ }^{10,12}$ and eating behavior ${ }^{10,12}$ were associated with large intervals between dental appointments, represented here by the last time the individual went to the dentist.

In relation to toothbrush replacement, which is another variable with a high explanatory capacity for characterizing the oral self-care variable, no patterns were found for a specific replacement time. ${ }^{17}$ Studies with university students have shown that residents in countries with better socioeconomic conditions replace their toothbrush more frequently ${ }^{26}$ than in countries with lower conditions. ${ }^{17}$ This finding could reflect the influential role played by recommendations from dentists, toothbrush manufacturers, and sellers. ${ }^{17}$

As mentioned above, females were found to take greater care than males in relation to practically all the variables forming the oral self-care indicator. Among the explanations for this finding is that preventive habits are more common among women, mainly due to aesthetic or social patterns., ${ }^{710,12}$ Although these variables are part of the characterization of the oral self-care indicator, no relation with gender was found in the present study, denoting that oral healthcare, in its broadest sense, is not influenced by gender. In addition, it has been suggested that a change in health patterns is taking place in the men's group, where there is increasing recognition of the importance of healthcare.

Greater recognition of the role of oral health was also observed among individuals with a better socioeconomic status. Although the literature points to socioeconomic status as one of the most important social determinants of oral health, $7,10,12 ; 13,19$ based on the purchasing power needed to purchase oral hygiene instruments ${ }^{12,19}$ and on regular dental visits, ${ }_{1}^{10,13}$ this association was not ascertained in the present study. The present study found that the level of education of the individual bears greater influence than purchasing power, inasmuch as educational level may reflect having knowledge about the importance and maintenance of healthy oral habits.

This assumption is reinforced by the results found in the present study. The individual's level of education was the variable most strongly associated with self-care. Illiterate, primary school and secondary school individuals were 11.20, 3.50, and 1.68 times, respectively, more likely to present inadequate oral health than individuals with higher educational levels.

The level of education plays an important role in oral self-care, because it provides greater access to information that supports the understanding of the health disease process, and the importance of using mechanisms to prevent oral problems and of regular dental services. ${ }^{7,10,13}$ In addition, education enhances the individual's ability to use such information efficiently, which is the basis for health empowerment. ${ }^{14}$ 
Bearing this in mind, it is important to invest in actions and services that offer and expand access to information, and in supporting health promoters, focused on improving individual experiences and overcoming health barriers. ${ }^{14,27,28}$ The development of personal skills and attitudes needs to be conducive to the acquisition of technical knowledge, which is the guiding axis for pursuing greater oral health equality. ${ }^{14,27,28,29}$

Self-perception of oral health is considered a multidimensional measure that reflects the individual's experience and the oral health condition in functional, social, and cultural terms. ${ }^{30}$ As investigated here, self-perception was also considered an important explanatory factor for oral self-care. This finding can be attributed to the fact that individuals with a positive self-perception of oral health are more predisposed to using health services regularly ${ }^{15,30}$ and to practicing adequate oral hygiene. ${ }^{31}$

In addition, tooth loss and the number of natural teeth in the mouth were also strongly associated with oral self-care. Individuals with large dental losses presented higher odds of inappropriate health habits. ${ }^{7,14,32}$ This situation seems to produce a cascade effect, where the more inadequate the oral care, the greater the chances of tooth loss. ${ }^{7,14,32}$ As shown, dental loss triggers a certain carelessness about health, leading to reduced self-esteem and feelings of rejection and isolation, thus interfering with personal relationships and the desire to seek care.,31

Dental loss is considered a marker of health inequalities, since it affects more individuals with a lower educational level and income, who have less access to dental and health promotion services. ${ }^{31,33,34}$ In this sense, broad-ranging strategies should be taken to minimize inequality in oral healthcare and offer the population a better quality of life.

Individuals with supplementary healthcare are more likely to have adequate oral self-care. The literature shows that people with dental insurance tend to use dental services more frequently, ${ }^{35}$ present better oral health conditions, ${ }^{36}$ and use more preventive methods than individuals without health insurance. ${ }^{7}$ Therefore, having health insurance may be related to greater access to dental services, and, consequently, to oral health information, resulting in healthier behaviors.
This indicates that strategies for public health services should be reviewed not only to increase access to dental care, but also to put forth healthpromoting strategies that allow users to have full and assisted oral healthcare.

In addition, the absence of regular physical activity and the smoking habit increase the chances of the individual presenting inadequate oral care by 2.77 and 2.18, respectively. Studies have shown that a sedentary lifestyle ${ }^{8,12,16}$ and tobacco use ${ }^{12}$ have been considered indicators of unhealthy habits. It is evident that lifestyle is directly related to oral habits, which must be taken into consideration in developing oral health promotion programs.

The findings of the present study should be used to guide the planning of preventive oral programs, aiming to enhance oral self-care in the Brazilian population. However, in addition to health promotion actions that focus on risk factors and self-care, public policies committed to improving socioeconomic conditions should be developed, especially regarding schooling, guaranteeing access to oral health services and the continuous qualification thereof. These measures are indispensable to bringing about changes in the oral health situation of the Brazilian population.?

\section{Limitations}

The results of the present study should be interpreted taking into account the type of research design, since cross-sectional studies allow hypotheses only about the associations found and not the causeand-effect relationship.

In addition, the dependent variable was measured by self-report, a condition that can overestimate the positive results, since individuals may report what they believe to be ideal and not what they actually practice. However, this limitation is likely to occur in any survey in which information is obtained by self-report. ${ }^{13}$

\section{Conclusion}

It was concluded that the level of education of the individual is one of the main factors for adherence to adequate oral self-care, followed by certain oral conditions, such as tooth loss. In addition, lifestyle seems to bear a significant influence. 


\section{References}

1. Ministério da Saúde (BR), Secretaria de Atenção à Saúde, Núcleo Técnico da Política Nacional de Humanização. Humaniza SUS: documento base para gestores e trabalhadores do SUS. Brasília, DF: Ministério da Saúde; 2008.

2. World Health Organization. Self-care in the context of primary health care: report of the Regional Consultation Bangkok, Thailand, 2009. 2009. New Delhi: World Health Organization; 2009.

3. Bub MBC, Medrano C, Silva CD, Wink S, Liss $P E$, Santos EKA. [The notion of care of the self and the concept of self-care in nursing]. Texto Contexto - Enferm. 2006;15(spe):152-7. Portuguese. http://dx.doi.org/10.1590/S0104-07072006000500018

4. Abreu W, Barroso C, Segadães MF, Teixeira S. Promotion of self-care in clinical practice: implications for clinical supervision in nursing. Int J Inf Educ Technol. 2015;5(1):6-9. https://doi.org/10.7763/IJIET.2015.V5.466

5. Ministério da Saúde (BR). Portaria $n^{\circ} 483$, de $1^{\circ}$ de abril de 2014. Redefine a Rede de Atenção à Saúde das Pessoas com Doenças Crônicas no âmbito do Sistema Único de Saúde (SUS) e estabelece diretrizes para a organização das suas linhas de cuidado. Diário Oficial União. 2 abr 2014.

6. Lange I, Urrutia M, Campos C, Gallegos E, Herrera LM, Jaimovich $S$ et al. [Strengthening self-care as a strategy for Primary Health Care: the contribution of health institutions in Latin America]. Geneva: OPAS; 2006.

7. . Davoglio RS, Aerts DR, Abegg C, Freddo SL, Monteiro L. [Factors associated with oral health habits and use of dental services by adolescents]. Cad Saude Publica. 2009;25(3):655-67. Portuguese. https://doi.org/10.1590/ S0102-311X2009000300020 PMID:19300854

8. Neamatollahi $H$, Ebrahimi M. Oral health behavior and its determinants in a group of Iranian students. Indian J Dent Res. 2010;21(1):84-8. https://doi.org/10.4103/0970-9290.62820

9. Folayan MO, Khami MR, Folaranmi N, Popoola BO, Sofola OO, Ligali TO et al. Determinants of preventive oral health behaviour among senior dental students in Nigeria. BMC Oral Health. 2013;13(28):28. https://doi.org/10.1186/1472-6831-13-28

10. Peltzer K, Pengpid S. Oral health behaviour and social and health factors in university students from 26 low, middle and high income countries. Int J Environ Res Public Health. 2014;11(12):12247-60. https://doi.org/10.3390/ijerph111212247

11. Iwuala SO, Umeizudike KA, Ozoh OB, Fasanmade OA. Oral self-care practices, dental attendance and selfperceived oral health status among internal medicine residents in Nigeria. Eur J Gen Dent. 2015;4(2):79-86. https://doi.org/10.4103/2278-9626.154179

12. Freddo SL. Aerts DRGC, Abegg C, Davoglio R, Vieira PC, Monteiro $L$ [Oral hygiene habits and use of dental services among teenage students in a city in southern Brazil]. Cad
Saude Publica. 2008;24(9):1991-2000. Portuguese. https://doi.org/10.1590/S0102-311X2008000900005

13. Machado LP, Camargo MB, Jeronymo JC, Bastos $G A$. Regular use of dental services among adults and older adults in a vulnerable region in Southern Brazil. Rev Saude Publica. 2012;46(3):526-33. https://doi.org/10.1590/S0034-89102012000300015

14. Haikal DS, Martins AM, Aguiar PH, Silveira MF, Paula AM, Ferreira EF. [Access to information on oral hygiene and tooth loss due to caries among adults]. Cien Saude Colet. 2014;19(1):287-300. https://doi.org/10.1590/1413-81232014191.2087

15. Silveira MF, Freire RS, Nepomuceno MO, Martins AM, Marcopito LF. [Tooth decay and associated factors among adolescents in the north of the State of Minas Gerais, Brazil: a hierarchical analysis]. Cien Saude Colet. 2015;20(11):3351-64. Portuguese. https://doi.org/10.1590/1413-812320152011.12262014

16. Vettore MV, Moyses SJ, Sardinha LMV, Iser BPM. [Socioeconomic status, toothbrushing frequency, and health-related behaviors in adolescents: an analysis using the PeNSE database]. Cad Saúde Pública, 2012;28(supl):101-13. Portuguese. https://doi.org/10.1590/S0102-311X2012001300011

17. Bashiru BO, Anthony IN. Oral self-care practices among university students in Port Harcourt, Rivers State. Niger Med J. 2014;55(6):486-9. https://doi.org/10.4103/0300-1652.144703

18. Attin T, Hornecker E. Tooth brushing and oral health: how frequently and when should tooth brushing be performed? Oral Health Prev Dent. 2005;3(3):135-40.

19. Abegg C. [Oral hygiene habits among Brazilian adults in an urban area of southern Brazil]. Rev Saude Publica. 1997;31(6):586-93. Portugues. https://doi.org/10.1590/S0034-89101997000700007

20. Brasil [Ministry of Planning, Budget and Management. Brazilian Institution of Geography and Statistics. National Health Survey 2013 - Perception of health status, lifestyles and chronic diseases]Brasília: Portuguese; 2014.

21. Instituto Brasileiro de Geografia e Estatística - IBGE. Pesquisa Nacional de Saúde 2013: percepção do estado de saúde, estilos de vida e doenças crônicas: Brasil, grandes regiões e unidades da Federação. Rio de Janeiro: Instituto Brasileiro de Geografia e Estatística; 2013.

22. Tan E, Daly C. Comparison of new and 3-month-old toothbrushes in plaque removal. J Clin Periodontol. 2002;29(7):645-50. https://doi.org/10.1034/j.1600-051X.2002.290709.x

23. Luchi CA, Peres KG, Bastos JL, Peres MA. Inequalities in self-rated oral health in adults. Rev Saude Publica. 2013;47(4):740-51. https://doi.org/10.1590/S0034-8910.2013047004364 
24. Frank E, Hall MA, Witten IH. Data mining: practical machine learning tools and techniques. 4th ed. San Francisco: Morgan Kaufmann; 2016.

25. Zadik Y, Galor S, Lachmi R, Proter N. Oral self-care habits of dental and healthcare providers. Int J Dent Hyg. 2008;6(4):354-60. https://doi.org/10.1111/i.1601-5037.2008.00334.x

26. Rimondini L, Zolfanelli B, Bernardi F, Bez C. Selfpreventive oral behavior in an Italian university student population. J Clin Periodontol. 2001;28(3):207-11. https://doi.org/10.1034/j.1600-051x.2001.028003207.x

27. Moimaz SA, Saliba O, Santos KT, Queiroz AP, Garbin CA. [Dental caries prevalence in pregnant women attending in the national health system in city of São Paulo state]. Rev.Odontol Araçatuba. 2011;32(1):44-8. Portuguese.

28. Garbin CA, Queiroz AP, Garbin AJ, Moimaz SA, Soares $G B$. Comparison of methods in oral health education from the perspective of adolescents. Oral Health Prev Dent. 2013;11(1):39-47. https://doi.org/10.3290/i.ohpd.a29374.

29. Garbin CA, Sumida DH, Santos RR, Chehoud KA, Moimaz SA. Oral health promotion during pregnancy. Rev Odontol UNESP. 2011;40(4):161-5.

30. Moura C, Gusmão ES, Santillo PM, Soares RS, Cimões R. [Self-rated oral health and associated factors among adults in rural settlements, Pernambuco State, Brazil]. Cad Saude Publica. 2014 Mar;30(3):611-22. Portugues. https://doi.org/10.1590/0102-311X00117012

31. Nico LS, Andrade SS, Malta DC, Pucca Júnior GA, Peres MA. Self-reported oral health in the Brazilian adult population: results of the 2013 National Health Survey. Cien Saude Colet. 2016 Feb;21(2):389-98. https://doi.org/10.1590/1413-81232015212.25942015

32. Saliba NA, Moimaz SA, Saliba O, Tiano AV. [Dental loss in a rural population and the goals established for the World Health Organization]. Cien Saude Colet. 2010;15 Suppl 1:1857-64. https://doi.org/10.1590/S1413-81232010000700099

33. Barbato PR, Peres KG. Contextual socioeconomic determinants of tooth loss in adults and elderly: a systematic review. Rev Bras Epidemiol. 2015;18(2):357-71. https://doi.org/10.1590/1980-5497201500020006

34. Prado RL, Saliba NA, Garbin CA, Moimaz SA. Oral impacts on the daily performance of Brazilians assessed using a sociodental approach: analyses of national data. Braz Oral Res. 2015;29(1):1-9. https://doi.org/10.1590/1807-3107BOR-2015.vol29.0086

35. Miranda CD, Peres MA. [Determinants of dental services utilization by adults: a population-based study in Florianópolis, Santa Catarina State, Brazil]. Cad Saude Publica. 2013;29(11):2319-32.Portuguese. https://doi.org/10.1590/0102-311x00139912

36. Leão MM, Garbin CA, Moimaz SA, Rovida TA. Oral health and quality of life: an epidemiological survey of adolescents from settlement in Pontal do Paranapanema/ SP, Brazil. Cien Saude Colet. 2015;20(11):3365-74. https://doi.org/10.1590/1413-812320152011.00632015 